\title{
Cross-Sectional Variations of Illiquidity on Stock Returns, Idiosyncratic Volatility Biases in the Shanghai A’ Share Stock Market
}

\author{
Chen Yang \\ Xi'an International Studies University, Xi'an, China
}

\begin{abstract}
Under the NTS Reform (Non-Tradable Share Reform), this paper explores the cross-sectional relations between illiquidity and stock returns by considering the idiosyncratic volatility biases in the Shanghai A' Share stock market. Differing from prior studies, stock returns are decreasing in a stock's illiquidity both before and after the NTS Reform. Regarding the negative relation between illiquidity and stock returns, we find that stock returns show no clear relation with illiquidity after controlling for idiosyncratic volatility biases. Furthermore, we use residual approach to eliminate the effect of idiosyncratic volatility, and find there exists a positive relation between illiquidity and stock returns after the NTS Reform.
\end{abstract}

Keywords: NTS reform, illiquidity, idiosyncratic volatility, Shanghai A’ Share stock market

\section{Introduction}

Market microstructure models have shown that liquidity is one of the most important market fractions that influence asset prices (e.g., Easley \& O’Hara, 1987). In a seminal paper, Amihud and Mendelson (1986) show a positive relation between illiquidity and stock returns by using the bid-ask spread for illiquidity proxy. Brennan and Subrahmanyam (1996), Brennan, Chordia, and Subrahmanyam (1998), Datar, Naik, and Radcliffe (1998), and Amihud (2002) all show that stocks with low liquidity acquire higher expected returns as compared to stocks with high liquidity. Pastor and Stambaugh (2003), Acharya and Pederson (2005), Chordia, Sarkar, and Subrahmanyam (2005), Liu (2006) have shown that illiquidity is important for explaining asset returns and should be priced by the market.

However, fewer studies attempt to simultaneously consider the effect of liquidity and idiosyncratic volatility on expected stock returns into account. O'Hara (2003) develops an asymmetric information asset pricing model that incorporates the transactions costs of liquidity as well as the risks of price discovery. In particular, Stoll $(1978)$ and Ho and Stoll $(1980 ; 1981)$ propose an inventory model that dealer provides

Acknowledgements: This work is financially supported by Ishii Memorial Securities Research Promotion Foundation and the Scientific Research Project of Xi'an International Studies University (No. 16XWC02). Also this work is the Scientific Research Program Funded by Shaanxi Provincial Education Department (Program No. 18JK0641). The author is greatly thankful to the Nippon Finance Association and Eleventh Annual Conference of the Asia-Pacific Economic Association for their helpful comments and suggestions.

Chen Yang, doctor of Economics, School of Japanese Studies, Xi'an International Studies University, Xi'an, China.

Correspondence concerning this article should be addressed to Chen Yang, No. 1, South Wenyuan Road, Guodu Educational Sci-tech Industrial Zone, Xi'an 710128, China. 
immediacy by investor trading to market who is faced with risks on his inventory, which is partly due to the de-diversification caused by dealing in few stocks (idiosyncratic volatility risk). Dealers are unwillingness to provide immediacy (liquidity) when they are faced with higher return uncertainty on their inventory. With information asymmetry, an increase in volatility of underlying security returns implies higher uncertainty about the expected value of the security, which leading a higher adverse selection cost faced by liquidity provider, due to the increased possibility of trading with informed traders. This in turn leads to lower liquidity due to higher transaction costs and higher volatility because of higher bid-ask bounce (see for Easley, Kiefer, \& O'Hara, 1996; O'Hara, 2003). Other studies like Easley and O'Hara (2010) develop a model in which illiquidity arises from uncertainty during financial crisis; Brunnermeier and Pedersen (2008) link the asset's market liquidity and traders' funding liquidity, and imply that market liquidity is related to volatility. ${ }^{1}$

Among empirical studies, Spiegel and Wang (2005) investigate the interaction relation between the two factors - idiosyncratic volatility and liquidity and find that the explanatory power of idiosyncratic volatility is strong and even could eliminates the liquidity effect on US stock market. Bao, Pang, and Wang (2011), Kalimipalli and Nayak (2012), and Kalimipalli, Nayak, and Perez (2013) examine the jointly effect of the two factors on bond market and find that both idiosyncratic volatility and liquidity remain their significant influence on bond yields. Han and Lesmond (2011) show that controlling for liquidity bias in the estimated idiosyncratic volatility eliminates the pricing ability of idiosyncratic volatility (e.g., Ang, Hodrick, Xing, \& Zhang, 2006; 2009; Bali \& Cakici, 2008; Bali, Cakici, \& Whitelaw, 2011; Fu, 2009; Huang, Liu, Rhee, \& Zhang, 2009; Khovansky \& Zhylyevskyy, 2013; Hou \& Loh, 2016) ${ }^{2}$. Motivated by these studies, we examine the cross-sectional correlations between illiquidity and stock returns by considering the idiosyncratic volatility bias in the Chinese stock market. As for our knowledge, there has no article to study the effect of liquidity on stock returns with considering idiosyncratic volatility.

Chinese stock market has developed such remarkably that catches a great deal of attention from the world in recent years. Different from developed markets like US, Europe countries, Japan, we conjecture that Chinese stock market may show some typical features related to Chinese investment and Chinese behavior due to the numerous constraints only in Chinese market ${ }^{3}$. The most represent feature is the Non-Tradable Share Reform (April 2005, hence for NTS Reform), which aimed at overcoming split share structures by converting non-tradable shares into tradable shares. This reform directly improves the market liquidity and influences volatility. Thus it is very necessary as well as important to study whether NTS Reform affects illiquidity, idiosyncratic volatility, or both. Therefore the purpose of this paper is to investigate correlations between illiquidity and stock returns by considering the idiosyncratic volatility bias under the NTS Reform in the Chinese stock market.

The results are as follows. Firstly, differing from prior studies, stock returns are decreasing in a stock's illiquidity (illiq_zero) both before the NTS Reform and after the NTS Reform. This finding means that investors require higher compensation on liquid stocks than illiquid stocks, which is inconsistent with illiquidity premium (e.g., Amihud \& Mendelson, 1986; Amihud, 2002; Pastor \& Stambaugh, 2003). Thus we call there exists illiquidity puzzle in the Chinese stock market.

\footnotetext{
${ }^{1}$ Vayanos and Wang (2011) show that the positive relationship between expected returns and idiosyncratic volatility might be partly due to illiquidity.

${ }_{2}^{2}$ Ang et al. (2006; 2009) examine the pricing ability of idiosyncratic volatility and find that stocks with high idiosyncratic volatility have earn lower average returns.

${ }^{3}$ Other features such as short-sales constraints are remained now, which also arises the transaction costs and information asymmetry, leading low liquidity and high volatility.
} 
To seek for the negative correlation between illiquidity and stock returns, we consider the impact of idiosyncratic volatility on illiquidity as well as stock returns by using bivariate sorts portfolio analysis. To this end, we firstly sort stocks into quintiles by idiosyncratic volatility, and then within each idiosyncratic volatility quintile portfolios, we further sort stocks into quintiles based on illiq_zero, and this produces rebalance every month. After considering the idiosyncratic volatility basis, stock returns show no clearly relations to illiquidity, especially after the NTS Reform. This result is similar with Spiegel and Wang (2005), who also show that idiosyncratic volatility reduces the pricing ability of liquidity.

Following Fama and French (2008), we use residual illiq_zero by orthogonalizing the idiosyncratic volatility from the illiq zero measure. And then we sort stocks into quintiles by the residual illiq zero and find that positive difference for arbitrage portfolio (lowest illiq_zero quintile-highest illiq_zero quintile) but insignificant before the NTS Reform, while there exists a positive relation between illiq_zero and stock returns after the NTS Reform.

Prior studies on Chinese stock market are all about the influence of liquidity on stock returns or idiosyncratic volatility on stock returns ${ }^{4}$. For example, Su and Mai (2004), Wu and Song (2007), Zhang, Tian, and Wirjanto (2009), Nayan and Zheng (2010), i.e., examine the relation between liquidity and stock returns by using turnover ratio as liquidity measure, and find a positive relation between illiquidity and stock returns. With the illiquidity measure of Amihud (2002), $\mathrm{Li}$ and $\mathrm{Wu}$ (2003) provide evidence that supports a negative relations between illiquidity and stock returns; whereas Nayan and Zheng (2010) show aggregate illiquidity is a priced risk factor, which is positively related to stock returns (see also for Chen, Tu, \& Lin, 2007). Other related studies like Jin and Yang (2002) explore the effects of stock price, trading volume and volatility on market liquidity, and find that factors such as trading volume, stock price and volatility of return can give significant explanation to different liquidity level.

Comparing with prior studies on Chinese stock market, this paper makes three efforts. It is the first attempt to study the jointly effect of liquidity and idiosyncratic volatility on stock returns with using a new illiquidity measure to capture the liquidity of Chinese stock market. Second, we consider the influences of the NTS Reform to examine whether the NTS Reform affects the relations between liquidity and idiosyncratic volatility or liquidity and returns. Third, we propose a residual approach to eliminate the impact of idiosyncratic volatility on liquidity.

The rest of this paper is organized as follows. Section 2 provides the data description, liquidity and idiosyncratic volatility measures used in this study. Section 3 presents the portfolio analyses for univariate sorts analysis and bivariate sorts analysis with considering the impact of idiosyncratic volatility. Section 4 presents illiq zero residual approach to further explore the correlation between illiq_zero and stock returns. Section 5 provides concluding comments.

\section{Data and Descriptive Statistics}

We obtain daily and monthly stock returns, market returns and trading volumes from CSMAR (China Stock Market \& Accounting Research) database over the period December 2000 through January 2012, which includes all common stocks traded on the Shanghai A' Share Stock Exchange. As discussed earlier, we focus

\footnotetext{
${ }^{4}$ Yang and Han (2009) document a negative relation between idiosyncratic volatility on stock returns, Chen et al. (2009) also obtain the similar results with Yang and Han (2009), while Deng and Zheng (2011) find that idiosyncratic volatility is positively related to stock returns.
} 
on the A' Share market since the size and the trading value of the A' Share market account for 80 percent of the whole stock market. We also use annual accounting data for calculating the book-to-market ratio (B/M) and market value (MV) from the balance sheet of each firm. In addition, monthly risk-free rate is converted from the annual risk free rate based on compound interest calculation from CSMAR database. Here we exclude stocks whose trading days in a month is less than 10 days.

Following Fama and French (1992; 1993), we form size portfolios and book-to-market portfolios to calculate SMB and HML factor. In the end of each year $t$ from 2001 to 2012, all common stocks are ranked based on market value and then split them into two groups, small and big ( $\mathrm{S}$ and B). We also break all these common stocks into three book-to-market equity groups based on the breakpoints for the bottom 30\% (Low), middle $40 \%$ (Medium), and top $30 \%$ (High) of the ranked values of $\mathrm{B} / \mathrm{M}$.

Then we construct six portfolios $(\mathrm{S} / \mathrm{L}, \mathrm{S} / \mathrm{M}, \mathrm{S} / \mathrm{H}, \mathrm{B} / \mathrm{L}, \mathrm{B} / \mathrm{M}, \mathrm{B} / \mathrm{H})$ from the intersections of the two MV and three $\mathrm{B} / \mathrm{M}$ groups. For example, the $\mathrm{S} / \mathrm{L}$ portfolio contains the stocks in the small MV group that are also in the low $\mathrm{B} / \mathrm{M}$ group, and the $\mathrm{B} / \mathrm{H}$ portfolio contains the big $\mathrm{MV}$ group that also have high $\mathrm{B} / \mathrm{M}$. Monthly value-weighted returns on the six portfolios are calculated each year. SMB is the difference between the returns on the small- $(\mathrm{S} / \mathrm{L}, \mathrm{S} / \mathrm{M}, \mathrm{S} / \mathrm{H})$ and big- $(\mathrm{B} / \mathrm{L}, \mathrm{B} / \mathrm{M}, \mathrm{B} / \mathrm{H})$ stock portfolios with about the same weighted average book-to-market equity. As the same way, HML means the difference between the returns on the low- (S/L, B/L) and high- $(\mathrm{S} / \mathrm{H}, \mathrm{B} / \mathrm{H})$ stock portfolios with about the same weighted average $\mathrm{MV}$.

\section{Estimation of Illiquidity and Idiosyncratic Volatility}

Consider that there has a large percentage of non-trading days due to high trading costs in Chinese stock market, we propose a new liquidity measure, Illiq zero - the revised version of Amihud (2002) for our illiquidity measure, which can be calculated as follows:

$$
\text { Illiq__Zero }_{i, t}=\left[\ln \left(\frac{1}{N_{i, t}} \sum_{t=1}^{N_{i, t}}\left|R_{i, d}\right| / V O L D_{i, d}\right)\right]+N T \%_{i, t}
$$

where $N_{i, t}$ is the number of days on which stock $i$ is traded in month $t,\left|R_{i, d}\right|$ is the absolute value of returns on stock $i$ on day $d$, and $V O L D_{i, d}$ is the Chinese yuan trading volume of stock $i$ on day $d . N T \%_{i, t}$ is the percentage of zero-return days within a month. Therefore, if the stock return on day $d$ is not zero, the new illiquidity measure is the logarithm of the Amihud illiquidity measure, whereas if the stock return on day $d$ is zero, the new illiquidity measure will be the same as that of Lesmond, Ogden, and Trzcinka (1999) ${ }^{5}$. This new illiquidity measure captures the price reaction to trading volume as well as the trading cost. Therefore, higher the new illiquidity measure, lower the stock liquidity.

Following Ang et al. (2006, 2009), we define idiosyncratic volatility as the standard deviation of the residuals from the Fama and French (1993) model. In each month, daily excess returns of individual stocks are regressed on the daily Fama-French three factors: the excess return on a broad market portfolio $\left(R_{m}-r_{f}\right)$, SMB and HML factors,

$$
R_{i d}-r_{f \mathrm{~d}}=\alpha_{i t}+\beta_{i t}\left(R_{m d}-r_{f d}\right)+s_{i t} S M B_{d}+h_{i t} H M L_{d}+\varepsilon_{i d}
$$

where $d$ is the subscript for the day and $t$ is the subscript for the month, $d \in t$, and $\beta_{i}, s_{i}, h_{i}$ are factor sensitivities or loadings. We run a time-series regression for each stock in each month. The idiosyncratic

\footnotetext{
${ }^{5}$ Lesmond et al. (1999) propose an illiquidity measure, by using the numbers of zero return days to numbers of trading days over some intervals, to capture the trading costs dimension of liquidity.
} 
volatility of a stock is computed as the standard deviation of the regression residuals.

Figure 1 plots the time-varying illiq zero measure and idiosyncratic volatility during the period January 2001 to December 2012. Overall, it seems to have a negative relation between illiq zero measure and idiosyncratic volatility since when the illiq zero is high, idiosyncratic volatility of the whole market comes to be low. On one hand, illiq_zero measure has a high value before the year of 2006, and sharply decreases during the period 2006 through 2012 due to NTSR. On the other hand, idiosyncratic volatility varies dramatically during the increasing period of Chinese stock market (2001-2003) and financial crisis (2007-2008) while displays flat in the rest period.

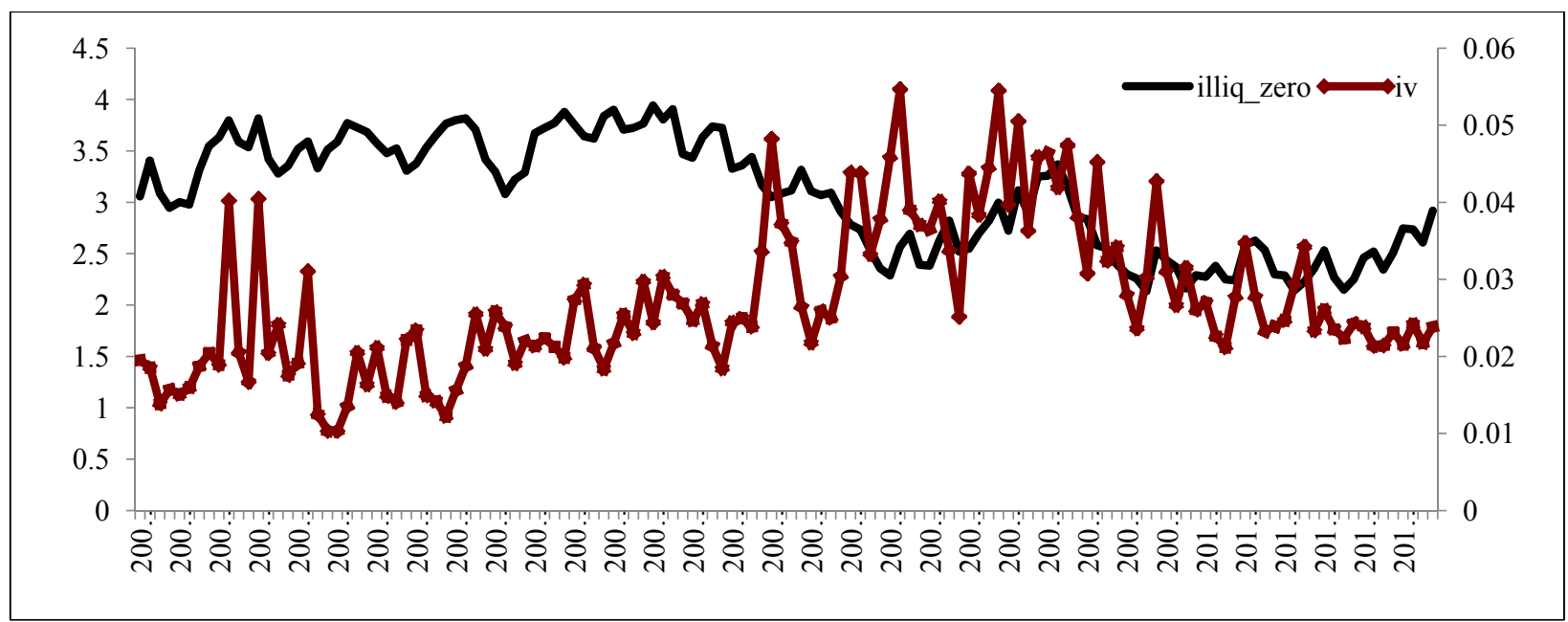

Figure 1. Illiq zero measure and idiosyncratic volatility. Notes. The sample includes stocks from Shanghai A' Share market through 2001 to 2012 . The illiq_zero is calculated as follows. Illiq_Zero ${ }_{i, t}=\left[\ln \left(\frac{1}{N_{i, t}} \sum_{t=1}^{N_{i, t}}\left|R_{i, d}\right| / V O L D_{i, d}\right)\right]+N T \%_{i, t}$, where $N_{i, m}$ is the number of trading volume days of stock $i$ in month $t,\left|R_{i, d}\right|$ is the absolute return on stock $i$ on day $d$, and VOLD $D_{i, d}$ is the Chinese yuan trading volume of stock $i$ on day $d . N T \%_{i, t}$ is the percentage of zero-return days within a month. Idiosyncratic volatility is defined as the standard deviation of the residuals from the Fama-French (1993) model.

\section{Summary Statistics}

Table 1 shows summary statistics for main variables examined here. Fama-French three factors, for example, SMB have a mean of -0.0073 while the mean value of HML is -0.0106 . As also shown in Figure 1 , illiq zero has a mean of 2.0197, varying from -3.7793 to 12.1131 . Idiosyncratic volatility varies from 0.0001 to 5.6571 and receives a mean of 0.0294 .

Correlations for these variables are provided in Table 2. Firstly, the relation between individual stock returns and SMB factor is positively 0.3073 , suggesting that small stocks have larger returns than big stocks, while the correlation for HML factor and stock returns shows negative. The correlation between illiq zero and stock returns is -0.1888 , and for illiq zero and market returns is -0.1900 , which is contrast with prior studies. Studies such as Amihud and Mendelson (1986), Amihud (2002) document that stocks with lower liquidity should be compensated by higher returns. Moreover, illiq zero and idiosyncratic volatility are negatively correlated with a value of -0.0795 .

To precisely observe these relations, we divide our sample period into two intervals-before NTSR and after NTSR - since NTSR may have influence on our variables. Figure 2 plots the cross-sectional relationship 
between illiq zero and stock returns before the NTS Reform and after the NTS Reform. Obviously, there has a negative relationship between illiq zero and stock returns before the NTS Reform, meaning that higher the liquidity, larger the stock returns. One possible interpretation is that individual investors dominate tradable share market and they are willing to hold more liquid stocks for seeking short-period profits. After the NTS Reform, we could not obtain any clearly relationship between illiq zero and stock returns. Figure 3 shows the cross-sectional relations between illiq zero and idiosyncratic volatility before the NTS Reform and after the NTS Reform. There exists a clearly positive relationship between illiq zero and idiosyncratic volatility after the NTS Reform, while it is negative before the NTS Reform.

Table 1

Summary Statistics

\begin{tabular}{llllll}
\hline Variable & Obs & Mean & Std. Dev. & Min & Max \\
\hline R & 78,162 & 0.0130 & 0.1430 & -0.7703 & 1.8945 \\
Size & 78,527 & 14.4319 & 1.3289 & 11.4431 & 21.3179 \\
B/M & 78,497 & 7.4670 & 0.9731 & 3.1713 & 12.7957 \\
Rm & 132 & 0.0070 & 0.0896 & -0.2693 & 0.2925 \\
SMB & 132 & -0.0073 & 0.0479 & -0.1504 & 0.0984 \\
HML & 132 & -0.0106 & 0.0302 & -0.1024 & 0.0637 \\
Illiq_zero & 78162 & 2.0197 & 1.5436 & -3.7793 & 12.1131 \\
Iv & 78162 & 0.0294 & 0.0438 & 0.0001 & 5.6571 \\
\hline
\end{tabular}

Notes. The sample includes stocks from Shanghai A' Share market between Jan 2001 to Dec 2012. Size is the market capitalization of all common stock, $\mathrm{B} / \mathrm{M}$ is the observation of book-to-market ratio of all common stocks. Rm is the return of market portfolios, SMB and HML are the returns of mimicking portfolios related to market value and book-to-market ratio, respectively. Illiq_zero is the illiquidity of all common stocks, which is calculated as follows. Illiq_Zero ${ }_{i, t}=\left[\ln \left(\frac{1}{N_{i, t}} \sum_{t=1}^{N_{i, t}}\left|R_{i, d}\right| /\right.\right.$ $V O L D i, d)+N T \% i, t$, where $N i, t$ is the number of trading volume days of stock $i$ in month $t, R i, d$ is the absolute return on stock $i$ on day $d$, and $V O L D_{i, d}$ is the Chinese yuan trading volume of stock $i$ on day $d . N T \%_{i, t}$ is the percentage of zero-return days within a month. And Iv is the idiosyncratic volatility of all common stocks, which is defined as the standard deviation of the residuals from the Fama-French (1993) model.

Table 2

Cross-sectional Correlations

\begin{tabular}{lllllll}
\hline & $\mathrm{R}$ & $\mathrm{Rm}$ & $\mathrm{SMB}$ & HML & Illiq_zero & Iv \\
\hline $\mathrm{R}$ & 1.0000 & & & & & \\
$\mathrm{Rm}$ & 0.6740 & 1.0000 & & & & \\
SMB & 0.3073 & 0.1453 & 1.0000 & & & \\
HML & -0.1104 & 0.0512 & -0.4239 & 1.0000 & & \\
Illiq_zero & -0.1888 & -0.1900 & -0.1221 & 0.1209 & 1.0000 & 1.0000 \\
Iv & 0.0277 & 0.0097 & 0.0360 & -0.0470 & -0.0795 & \\
\hline
\end{tabular}

Notes. The sample includes stocks from Shanghai A' Share market between Jan 2001 to Dec 2012. Size is the market capitalization of all common stock, B/M is the observation of book-to-market ratio of all common stocks. Rm is the return of market portfolios, SMB and HML are the returns of mimicking portfolios related to market value and book-to-market ratio, respectively. Illiq_zero is the illiquidity of all common stocks, which is calculated as follows. Illiq_Zero ${ }_{i, t}=\left[\ln \left(\frac{1}{N_{i, t}} \sum_{t=1}^{N_{i, t}}\left|R_{i, d}\right| /\right.\right.$ $\left.\left.V O L D_{i, d}\right)\right]+N T \%_{i, t}$, where $N_{i, t}$ is the number of trading volume days of stock $i$ in month $t,\left|R_{i, d}\right|$ is the absolute return on stock $i$ on day $d$, and $V O L D_{i, d}$ is the Chinese yuan trading volume of stock $i$ on day $d . N T \%_{i, t}$ is the percentage of zero-return days within a month. Iv is the idiosyncratic volatility of all common stocks, which is defined as the standard deviation of the residuals from the Fama-French (1993) model. 
We sort stocks into quintiles by illiq_zero, form equally weighted illiq zero quintile portfolios. The summary statistics of these illiq zero quintile portfolios are shown in Table 3. The Amihud measure, which is defined by the price impact to trading volume, increased monotonically across all illiq zero quintiles, indicating our new measure, illiq zero is highly correlated with Amihud (2002). The idiosyncratic volatility are also shown to decrease (except for illiq zero quintile 1), which is consistent with Table 2, though it is not obvious. Also with the increasing of illiq zero, size and book-to-market value for illiq zero quintiles reduce monotonically.
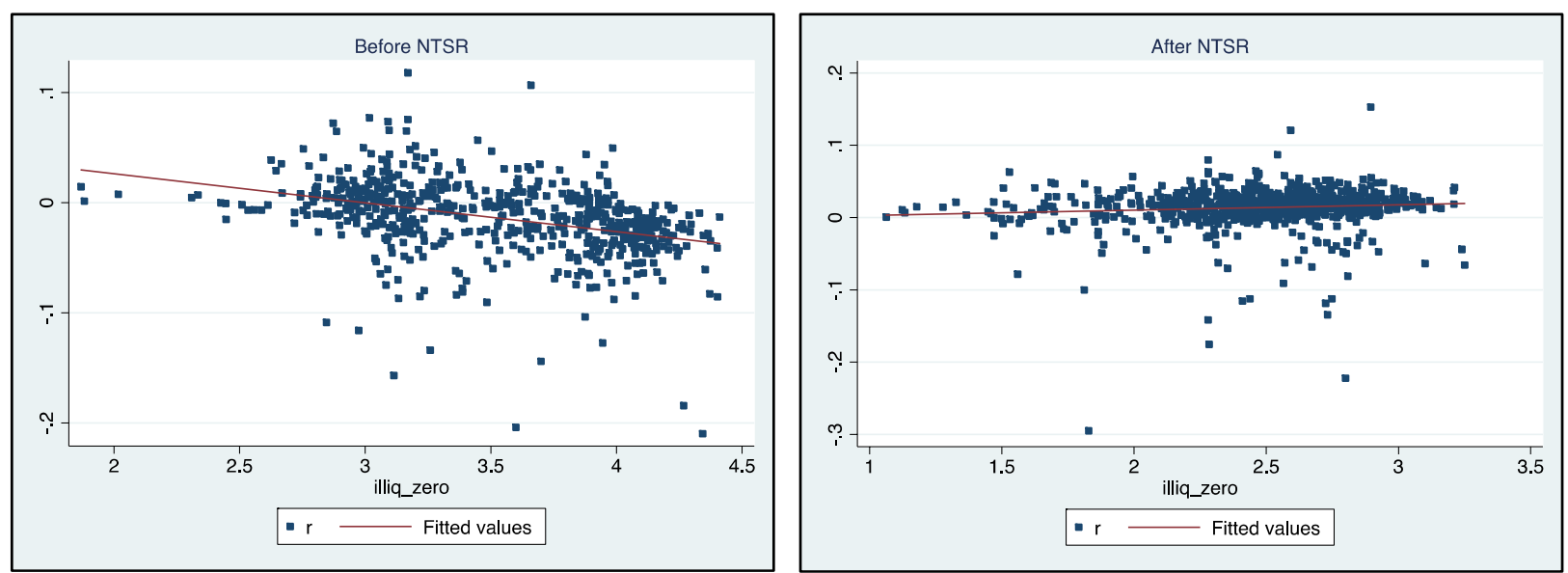

Figure 2. Cross-sectional relations between illiq zero and return. Notes. The sample includes stocks from Shanghai A' Share market within two periods - before NTS Reform (Jan 2001 to Apr 2005) and after NTS Reform (Oct 2008 to Dec 2012). $r$ represents the returns of each firm. The illiq_zero is calculated as follows. Illiq_Zero $_{i, t}=\left[\ln \left(\frac{1}{N_{i, t}} \sum_{t=1}^{N_{i, t}}\left|R_{i, d}\right| / V O L D_{i, d}\right)\right]+N T \%_{i, t}$, where $N_{i, t}$ is the number of trading volume days of stock $i$ in month $t,\left|R_{i, d}\right|$ is the absolute return on stock $i$ on day $d$, and $V O L D_{i, d}$ is the Chinese yuan trading volume of stock $i$ on day $d . N T \%_{i, t}$ is the percentage of zero-return days within a month.
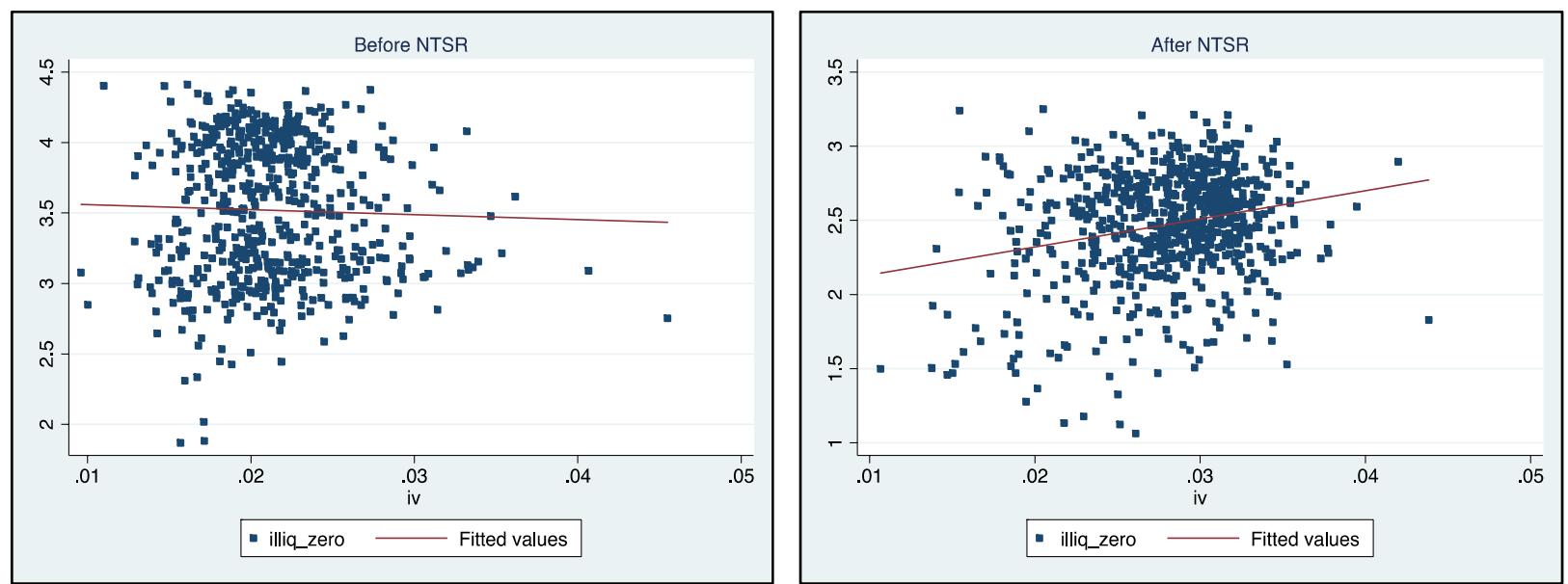

Figure 3. Cross-sectional relations between illiq_zero and idiosyncratic volatility. Notes. The sample includes stocks from Shanghai A' Share market within two periods-before the NTS Reform (Jan 2001 to Apr 2005) and after the NTS Reform (Oct 2008 to Dec 2012). The illiq_zero is calculated as follows. Illiq_Zero ${ }_{i, t}=\left[\ln \left(\frac{1}{N_{i, t}} \sum_{t=1}^{N_{i, t}}\left|R_{i, d}\right| /\right.\right.$ $V O L D i, d)+N T \% i, t$, where $N i, t$ is the number of trading volume days of stock $i$ in month $t, R i, d$ is the absolute return on stock $i$ on day $d$, and $V O L D_{i, d}$ is the Chinese yuan trading volume of stock $i$ on day $d . N T \%_{i, t}$ is the percentage of zero-return days within a month. Idiosyncratic volatility is defined as the standard deviation of the residuals from the Fama-French (1993) model. 
Table 3

Correlations of Various Variables on Portfolios Sorted by Illiq_zero

\begin{tabular}{llllll}
\hline & Illiq_zero & Amihud & Iv & Lnsize & lnbk \\
\hline 1 (Low) & 2.355 & 0.044 & 0.0280 & 15.591 & 16.902 \\
& $(0.58)$ & $(0.05)$ & $(0.01)$ & $(1.45)$ & $(1.96)$ \\
2 & 2.821 & 0.112 & 0.0282 & 14.656 & 15.674 \\
3 & $(0.54)$ & $(0.12)$ & $(0.01)$ & $(1.09)$ & $(1.15)$ \\
& 3.057 & 0.194 & 0.0280 & 14.289 & 15.331 \\
4 & $(0.56)$ & $(0.22)$ & $(0.01)$ & $1.03)$ & $(1.02)$ \\
& 3.268 & 0.305 & 0.0275 & $(1.01)$ & $(0.99)$ \\
5 (High) & $(0.57)$ & $(0.36)$ & $(0.01)$ & 13.674 & 14.835 \\
& 3.580 & 0.541 & 0.0272 & $(0.98)$ & $(0.98)$ \\
\hline
\end{tabular}

Notes. The sample includes stocks from Shanghai A' Share market within two periods-before the NTS Reform (Jan 2001 to Apr 2005) and after the NTS Reform (Oct 2008 to Dec 2012). This table presents the means and standard deviation (in parentheses) for quintile sorts by illiq_zero. The illiq_zero is calculated as follows. Illiq_Zero ${ }_{i, t}=\left[\ln \left(\frac{1}{N_{i, t}} \sum_{t=1}^{N_{i, t}}\left|R_{i, d}\right| / V O L D_{i, d}\right)\right]+N T \%_{i, t}$, where $N_{i, t}$ is the number of trading volume days of stock $i$ in month $t,\left|R_{i, d}\right|$ is the absolute return on stock $i$ on day $d$, and $V O L D_{i, d}$ is the Chinese yuan trading volume of stock $i$ on day $d . N T \%_{i, t}$ is the percentage of zero-return days within a month. Amihud is the illiquidity measure of Amihud (2002), defined as the price impact caused by trading volume. Idiosyncratic volatility is defined as the standard deviation of the residuals from the Fama-French (1993) model. Lnsize and lnbk are the logarithm of size and book value.

\section{Univariate and Bivariate Portfolio Analysis}

In this section, we form portfolios based on one- and two-way sorts to explore the cross-sectional relations between illiquidity and stock returns both before and after the NTS Reform. As numerous studies have document that illiquidity is highly related to idiosyncratic volatility (e.g. Ho \& Stoll, 1978; Brunnermeier \& Pederson, 2005), we consider the impact of idiosyncratic volatility in two-way sorts portfolio analysis.

\section{Univariate Sorted Portfolio Returns}

We sort stocks into quintiles based on their monthly estimates of illiq zero, form equally weighted quintile-sorted portfolios, and then difference the lowest and highest illiq zero quintiles. Specifically, each month, stocks are sorted into five quintiles based on the illiq zero and then rebalanced. We then regress the quintile portfolio returns against either the CAPM model or the three-factor (Fama-French) model to estimate the CAPM or the Fama-French alpha, respectively. We finally compare the performance between the portfolio with the lowest illiq zero (1 Low) and the portfolio with highest illiq_zero (5 High). The difference is the abnormal return one would earn on a zero-cost (arbitrage) portfolio formed by taking a long position in the lowest-quintile portfolio and taking a short position in the highest-quintile portfolio (P1-P5).

The results are presented in Table 4, with Panel A focusing on the results before the NTS Reform and Panel B focusing on results after the NTS Reform. As shown in Panel A of Table 4, the raw return on quintile 1 (lowest illiq_zero) is $0.692 \%$ on quantile 5 (highest illiq_zero) is $-2.669 \%$ per month. This results a difference of $3.361 \%$ in the arbitrage portfolio, with a $t$-statistic of 19.00 . And the decreasing trend performs monotonic, which is supportive of Figure 2, meaning higher the liquidity, larger the stock returns. After controlling for CAPM or the Fama-French model, the adjusted returns remain decreasing with illiq zero. For example, the Fama-French alpha of the arbitrage portfolio $(\mathrm{P} 1=\mathrm{P} 5)$ has earned a significantly positive return of $1.708 \%(t=$ 
2.93). These results suggest that including the market return, size and value factor do not sufficiently control for the effect of illiq zero on stock returns.

Table 4

Returns on Portfolios Sorted by Illiq_zero

\begin{tabular}{|c|c|c|c|c|c|c|}
\hline \multicolumn{7}{|c|}{ Panel A: Before NTS Reform } \\
\hline & 1 (Low) & 2 & 3 & 4 & 5 (High) & P1-P5 \\
\hline \multirow[t]{2}{*}{$\mathrm{r}$} & 0.692 & -0.887 & -1.762 & -2.205 & -2.669 & 3.361 \\
\hline & 5.26 & -6.75 & -13.83 & -18.51 & -22.54 & 19.00 \\
\hline \multirow[t]{2}{*}{ CAPM alpha } & 1.881 & 0.506 & -0.301 & -0.719 & -1.253 & 3.134 \\
\hline & 16.70 & 4.85 & -3.15 & -8.76 & -14.71 & 12.60 \\
\hline \multirow[t]{2}{*}{ FF-3 alpha } & 1.378 & 0.507 & 0.252 & 0.047 & -0.33 & 1.708 \\
\hline & 10.61 & 4.18 & 2.31 & 0.51 & -3.53 & 2.93 \\
\hline \multicolumn{7}{|c|}{ Panel B : After NTS Reform } \\
\hline & 1 (Low) & 2 & 3 & 4 & 5 (High) & P1-P5 \\
\hline \multirow[t]{2}{*}{$\mathrm{r}$} & 2.135 & 2.089 & 2.045 & 1.564 & 1.270 & 0.865 \\
\hline & 10.49 & 10.44 & 10.32 & 8.09 & 6.85 & 3.14 \\
\hline \multirow[t]{2}{*}{ CAPM alpha } & 1.232 & 1.221 & 1.185 & 0.682 & 0.394 & 0.838 \\
\hline & 8.11 & 7.87 & 7.76 & 4.74 & 2.98 & 2.68 \\
\hline \multirow[t]{2}{*}{ FF-3 alpha } & 0.799 & 0.471 & 0.409 & 0.228 & -0.11 & 0.909 \\
\hline & 4.77 & 2.89 & 2.61 & 1.55 & -0.83 & 0.71 \\
\hline
\end{tabular}

Notes. The sample includes stocks from Shanghai A' Share market within two periods-before NTS Reform (Jan 2001 to Apr 2005) and after NTS Reform (Oct 2008 to Dec 2012). Stocks are ranked into quintiles on the basis of their illiq zero every month. Panel A and B present the monthly raw returns, adjusted returns (alpha) relative to CAPM, as well as adjusted returns (FF-3 alpha) relative to Fama-French 3 factor models before and after NTSR, respectively. The column (P1-P5) reports the return differences between low illiq_zero portfolio and high illiq_zero portfolio. The illiq_zero is calculated as follows. Illiq_Zero ${ }_{i, t}=$ $\left[\ln \left(\frac{1}{N_{i, t}} \sum_{t=1}^{N_{i, t}}\left|R_{i, d}\right| / V O L D_{i, d}\right)\right]+N T \%_{i, t}$, where $N_{i, t}$ is the number of trading volume days of stock $i$ in month $t,\left|R_{i, d}\right|$ is the absolute return on stock $i$ on day $d$, and $V O L D_{i, d}$ is the Chinese yuan trading volume of stock $i$ on day $d$. $N T \%_{i, t}$ is the percentage of zero-return days within a month.

In Panel B of Table 4 (After the NTS Reform), which the raw return as well as the CAPM and Fama-French alpha show similar trend with Panel A. The Fama-French alpha declines from $2.135 \%$ to $1.270 \%$ with the increasing of illiq zero, which yields a positive alpha of $0.909 \%$ per month.

Notable in the results is the monotonically decreasing trend of stock returns from the lowest-ranked illiq zero quintile to the highest-ranked illiq_zero quintile. This means investors would earn a positive return on arbitrage portfolio formed by taking long positions in lowest illiq_zero quintile and taking short positions in the highest illiq zero quintile portfolio. Therefore we call there exists an illiquidity puzzle in Chinese stock market.

\section{Bivariate Sorted Portfolio Returns}

We then form two-way sorted portfolios to simultaneously control for the impact of idiosyncratic volatility while examining the cross-sectional effect of illiquidity on stock returns. Each month, we sort stocks into quintiles by idiosyncratic volatility firstly, and then we form portfolios by illiq zero into quintile for each idiosyncratic volatility quintile. This formation would yield 25 idiosyncratic volatility-illiq zero portfolios. Table 5 reports the Fama-French alpha both before (Panel A) and after (Panel B) the NTS Reform. The column (P1-P5) shows the difference on portfolio formed by taking long positions in lowest illiq zero quintile and 
taking short positions in highest illiq_zero quintile. The last row- "Control for Iv" shows the Fama-French alpha across illiq zero quintiles for a portfolio that is equally weighted across idiosyncratic volatility quintiles.

Table 5

Portfolios Sorted by Illiq_zero After Controlling for Idiosyncratic Volatility, FF 3 Factor Alphas

\begin{tabular}{|c|c|c|c|c|c|c|}
\hline \multicolumn{7}{|c|}{ Panel A : Before NTS Reform } \\
\hline & Illiq_zero 1 (Low) & 2 & 3 & 4 & 5 (High) & $\mathrm{P} 1-\mathrm{P} 5$ \\
\hline \multirow[t]{2}{*}{ Iv 1 (Low) } & 0.604 & 0.223 & -0.126 & -0.260 & -0.940 & 1.544 \\
\hline & 3.27 & 1.16 & -0.72 & -1.58 & -6.25 & 5.65 \\
\hline \multirow[t]{2}{*}{2} & 0.720 & 0.542 & -0.238 & -0.387 & -0.457 & 1.177 \\
\hline & 3.36 & 2.53 & -1.30 & -2.33 & -3.15 & 2.54 \\
\hline \multirow[t]{2}{*}{3} & 0.781 & 0.221 & -0.175 & -0.491 & -0.391 & 1.172 \\
\hline & 3.04 & 0.96 & -0.91 & -2.96 & -2.38 & 1.85 \\
\hline \multirow[t]{2}{*}{4} & 0.569 & 0.177 & 0.461 & -0.267 & -0.190 & 0.759 \\
\hline & 2.02 & 0.69 & 2.01 & -1.29 & -0.96 & 0.80 \\
\hline \multirow[t]{2}{*}{ Iv 5 (High) } & 3.415 & 2.036 & 1.248 & 1.303 & 0.934 & 2.481 \\
\hline & 8.38 & 5.54 & 3.53 & 4.08 & 2.92 & 2.59 \\
\hline \multirow[t]{2}{*}{ Control for Iv } & 1.219 & 0.642 & 0.238 & -0.018 & -0.209 & 1.428 \\
\hline & 9.47 & 5.36 & 2.18 & -0.18 & -2.19 & 1.87 \\
\hline \multicolumn{7}{|c|}{ Panel B : After NTS Reform } \\
\hline & Illiq_zero 1 (Low) & 2 & 3 & 4 & 5 (High) & $\mathrm{P} 1-\mathrm{P} 5$ \\
\hline \multirow[t]{2}{*}{ Iv 1(Low) } & -0.968 & -1.495 & -1.514 & -1.588 & -1.478 & 0.510 \\
\hline & -4.72 & -6.53 & -6.45 & -6.91 & -7.77 & 7.53 \\
\hline \multirow[t]{2}{*}{2} & -1.382 & -1.312 & -0.892 & -1.726 & -1.932 & 0.550 \\
\hline & -4.92 & -4.86 & -3.58 & -7.77 & -9.18 & 7.88 \\
\hline \multirow[t]{2}{*}{3} & -0.592 & -1.258 & -1.075 & -1.433 & -1.597 & 1.005 \\
\hline & -1.87 & -4.17 & -3.72 & -5.43 & -7.09 & 5.88 \\
\hline \multirow[t]{2}{*}{4} & 1.108 & 0.248 & -0.076 & -0.067 & 0.176 & 0.932 \\
\hline & 3.19 & 0.73 & -0.23 & -0.22 & 0.62 & 0.56 \\
\hline \multirow[t]{2}{*}{ Iv 5 (High) } & 6.523 & 5.469 & 5.421 & 5.731 & 4.660 & 1.863 \\
\hline & 13.19 & 11.15 & 12.16 & 12.11 & 10.87 & 10.18 \\
\hline \multirow[t]{2}{*}{ Control for Iv } & 0.941 & 0.335 & 0.376 & 0.188 & -0.027 & 0.968 \\
\hline & 5.63 & 2.05 & 2.46 & 1.24 & -0.20 & 0.18 \\
\hline
\end{tabular}

Notes. The sample includes stocks from Shanghai A' Share market within two periods - before NTSR (Jan 2001 to Apr 2005) and after NTSR (Oct 2008 to Dec 2012). In each month, stocks are ranked into quintiles on the basis of their idiosyncratic volatility firstly, and then sorted (into quintiles) by their illiq zero in each idiosyncratic volatility quintile. Panel A and B present the monthly adjusted returns (alpha) relative to Fama-French 3 factor models before and after NTSR, respectively. The illiq zero is calculated as follows. Illiq_Zero ${ }_{i, t}=\left[\ln \left(\frac{1}{N_{i, t}} \sum_{t=1}^{N_{i, t}}\left|R_{i, d}\right| / V O L D_{i, d}\right)\right]+N T \%_{i, t}$, where $N_{i, t}$ is the number of trading volume days of stock $i$ in month $t,\left|R_{i, d}\right|$ is the absolute return on stock $i$ on day $d$, and $V O L D_{i, d}$ is the Chinese yuan trading volume of stock $i$ on day $d . N T \%_{i, t}$ is the percentage of zero-return days within a month. And idiosyncratic volatility is defined as the standard deviation of the residuals from the Fama-French (1993) model.

Before the NTS Reform, the decreasing trend is also matched in each idiosyncratic volatility quintile (Iv $1 \sim \operatorname{Iv} 5$ ). That is lowest illiq_zero quintile 1 which has earned largest returns while highest illiq zero quintile 5 has earned lowest returns. The Fama-French alphas on arbitrage portfolios (P1-P5) are all positive, but not all of these results are significant. For instance, holding for idiosyncratic volatility quintile 4, the Fama-French alphas are decreasing from $0.569 \%$ to $-0.190 \%$, which yields a positive value of $0.759 \%$, while the $t$-statistic is 
0.80. Furthermore, in the "Control for Iv" row, the Fama-French alpha shows a monotonically decreasing trend and the result on (P1-P5) is positively $1.428 \%$, but insignificant. Thus idiosyncratic volatility seems to have some impact on the relation between illiq zero and stock returns.

We now turn to the results after the NTS Reform. According to each idiosyncratic volatility quintile, the Fama-French alphas in arbitrage portfolios (P1-P5) are all positive, but the decreasing trend is not all monotonically across each idiosyncratic volatility quintiles. For idiosyncratic volatility quintile 2 , the Fama-French alpha in illiq zero quintile 3 is largest, $-0.892 \%$, while the result in illiq zero quintile 1 is $-1.382 \%$. After controlling for idiosyncratic volatility (the row "Control for Iv"), illiq zero quintile 1 has earned largest value of $0.941 \%$, then illiq zero quintile 3 is $0.376 \%$, illiq zero quintile 2 is $0.335 \%$, illiq zero quintile 4 is $0.188 \%$, illiq_zero quintile 5 has earned smallest value of $-0.027 \%$. However, only the result of illiq zero quintile 1 is significant under $1 \%$ statistic level. Finally, the $t$-statistic on the arbitrage portfolio (P1-P5) is only 0.18 . Considering the impact of idiosyncratic volatility, the negative relation between illiq zero and stock returns is eliminated.

In sum, there exists illiquidity puzzle in Chinese stock market both before and after the NTS Reform. However, the puzzle could be partly eliminated by controlling for the impact of idiosyncratic volatility, especially after the NTS Reform. We provide the following approach to further explore the illiquidity puzzle with the effect of idiosyncratic volatility.

\section{Illiq_Zero Regression Residual Approach}

The bivariate sorts portfolio analysis makes it clear that the correlation between illiq zero and stock returns may not provide a conclusive test without considering the impact of idiosyncratic volatility. As inventory control model implies, sorting on illiq_zero could be in effect sorting on the idiosyncratic volatility. Thus, in effort to purge the idiosyncratic volatility effects from the illiq zero, we provide a residual illiq zero as a sorting variable (e.g. Chen et al., 2002; Fama \& French, 2008). The residual illiq zero is estimated by regressing the illiq zero on idiosyncratic volatility and then obtains the residual of this regression. This approach will orthogonalize the idiosyncratic volatility from the illiq zero measure by using Fama-MacBeth setting. Therefore we could isolate the impact of idiosyncratic volatility to examine the correlation between illiq_zero and stock returns.

\section{The Relation Between Illiq_Zero and Idiosyncratic Volatility}

We present in Table 6 a series of Fama-MacBeth (1973) regressions. We implement the Fama-MacBeth regressions as follows. Each month, we run a separate cross-sectional regression before as well as after the NTS Reform. We repeat such cross-sectional regressions for 52 months before NTSR and 39 months after NTS Reform, this gives us a total of 10,475 regressions before NTS Reform and 26,089 regressions after NTS Reform. Table 6 reports the mean coefficients across these regressions, along with the associated $t$-statistics and the adjusted $R$-squared values.

Before the NTS Reform, the idiosyncratic volatility is negatively related to illiq zero, which is different with prior studies. In contrast, the correlation between idiosyncratic volatility and illiq zero turns to positive after the NTS Reform. As we noted above, the composition on tradable share market has changed through the NTS Reform, and a large population of institutional investors or legal persons enters to the market. These changes directly influence the liquidity and volatility in the Chinese stock market and cause market to be more 
efficient and close to developed markets (i.e. US stock market). Thus it is reasonable to explain the strong positive relation between illiq_zero and idiosyncratic volatility after the NTS Reform.

Table 6

Illiq_zero and Idiosyncratic Volatility

\begin{tabular}{|c|c|c|c|c|c|c|}
\hline \multicolumn{7}{|c|}{ Dependent variable: Illiq_zero } \\
\hline & Coef. & & Std. Err. & $t$-value & No. of Obs & Adj. $R^{2}$ \\
\hline \multicolumn{7}{|c|}{ Before NTS Reform } \\
\hline Iv & -4.886 & $* * *$ & 1.68 & -2.91 & & \\
\hline _cons & 3.549 & $* * *$ & 0.05 & 78.18 & 10,475 & $1.13 \%$ \\
\hline \multicolumn{7}{|c|}{ After NTS Reform } \\
\hline $\mathrm{Iv}$ & 5.760 & $* * *$ & 0.23 & 24.98 & & \\
\hline _cons & 2.312 & $* * *$ & 0.01 & 337.56 & 26,089 & $2.21 \%$ \\
\hline
\end{tabular}

Notes. The sample includes stocks from Shanghai A' Share market within two periods-before NTS Reform (Jan 2001 to Apr 2005) and after NTS Reform (Oct 2008 to Dec 2012). The table presents Fama-MacBeth regression results of the illiq zero, estimated using Illiq_Zero ${ }_{i, t}=\left[\ln \left(\frac{1}{N_{i, t}} \sum_{t=1}^{N_{i, t}}\left|R_{i, d}\right| / V O L D_{i, d}\right)\right]+N T \%_{i, t}$, where $N_{i, t}$ is the number of trading volume days of stock $i$ in month $t,\left|R_{i, d}\right|$ is the absolute return on stock $i$ on day $d$, and $V O L D_{i, d}$ is the Chinese yuan trading volume of stock $i$ on day $d . N T \%_{i, t}$ is the percentage of zero-return days within a month on the influence of idiosyncratic volatility, which is defined as the standard deviation of the residuals from the Fama-French (1993) model. Significance at the 1\% level is given by $* * *$.

\section{Residual Illiq_zero Sorted Portfolio Analysis}

Each month, we sort stocks into quintiles by the estimated residual illiq_zero, form equally weighted quintile portfolios, and compare the performance of the quintile portfolios and the (P1-P5) arbitrage portfolio. Table 7 reports the cross-sectional raw returns, CAPM- $\alpha$, Fama-French- $\alpha$ on residual illiq zero quintile portfolios before the NTS Reform (Panel A) and after the NTS Reform (Panel B).

As shown in Panel A of Table 7 before the NTS Reform, the raw returns of the residual illiq zero quintile portfolios perform a decreasing trend, which is similar with the results of illiq zero quintiles. And the arbitrage portfolio (P1-P5) has earned a return of $0.377 \%$ per month, with a $t$-statistic of 1.91 . However, among the Fama-French alphas of the residual illiq_zero quintiles, only the residual illiq_zero quintile 1 is significant. The lack of significance in abnormal performance extends to the (P1-P5) extreme quintile difference (from the case of $1.888 \%$ shown in Panel A of Table 7).

Conversely, after the NTS Reform in Panel B, the results are remarkable. The negative correlations between illiq_zero and stock returns are converted, indicating that stock returns are increasing with illiq zero. Illiq zero quintile 1 earns lowest raw return of $-0.770 \%$, then illiq_zero quintile 2 is $-0.223 \%$, illiq zero quintile 3 is 0.294 , illiq_zero quintile 4 is $2.065 \%$ and illiq_zero quintile 5 earns largest raw return of $7.708 \%$, and all are significant. Also the CAPM or Fama-French alpha of residual illiq zero quintiles shows a monotonically increasing trend with residual illiq zero. The raw return of the arbitrage portfolio (P1-P5) is significantly $-8.478 \%$, suggesting that taking long positions in the highest illiq_zero quintile and taking short positions in the lowest illiq_zero quintile would earn $8.478 \%$ per month. After adjusted by CAPM model or Fama-French three-factor model, the alpha is reduced to $8.084 \%$ (CAPM alpha) or $6.963 \%$ (Fama-French alpha), but still significant at the $1 \%$ level.

These results are indicative of the "illiquidity puzzle" after removing the impact of idiosyncratic volatility on illiq_zero. In particular, after the NTS Reform, investors require profits when they taking long positions in 
illiquid stocks. The result also implies that the NTS Reform has improved the liquidity and volatility of tradable share market and further promotes the market efficiency.

Table 7

Returns on Portfolios Sorted by Residual Illiq_zero

\begin{tabular}{lllllll}
\hline Panel A: Before NTS Reform & & & & & & \\
\hline & 1 (Low) & 2 & 3 & 4 & 5 (High) & P1-P5 \\
\hline r & -0.694 & -1.788 & -1.818 & -1.478 & -1.071 & 0.377 \\
CAPM alpha & -3.94 & -13.78 & -15.76 & -13.98 & -12.02 & 1.91 \\
& 1.148 & -0.240 & -0.433 & -0.221 & -0.152 & 1.300 \\
& 7.99 & -2.55 & -5.26 & -2.94 & -2.20 & 1.36 \\
FF-3 alpha & & & & & \\
& 1.780 & 0.168 & -0.013 & 0.035 & -0.108 & 1.888 \\
\hline Panel B : After NTS Reform & 10.97 & 1.55 & -0.14 & 0.41 & -1.34 & 0.85 \\
\hline & 1 (Low) & 2 & & & 5 (High) & P1-P5 \\
\hline r & -0.770 & -0.223 & 0.294 & 2.065 & 7.708 & -8.478 \\
& -5.93 & -1.39 & 1.63 & 10.30 & 29.60 & -29.07 \\
CAPM alpha & -1.445 & -1.038 & -0.586 & 1.116 & 6.639 & -8.084 \\
FF-3 alpha & -15.47 & -9.41 & -4.69 & 7.91 & 33.35 & -42.67 \\
& -1.410 & -1.452 & -1.194 & 0.275 & 5.553 & -6.963 \\
\hline
\end{tabular}

Notes. The sample includes stocks from Shanghai A' Share market within two periods-before NTS Reform (Jan 2001 to Apr 2005) and after NTS Reform (Oct 2008 to Dec 2012). Stocks are ranked into quintiles on the basis of their residual illiq zero. Residual illiq zero is estimated by regressing the illiq zero estimate on idiosyncratic volatility. Panel A and B present the monthly raw returns, adjusted returns (alpha) relative to CAPM, as well as adjusted returns (FF-3 alpha) relative to Fama-French 3 factor models before and after NTSR, respectively. The illiq_zero is calculated as follows. Illiq_Zero ${ }_{i, t}=\left[\ln \left(\frac{1}{N_{i, t}} \sum_{t=1}^{N_{i, t}}\left|R_{i, d}\right| /\right.\right.$ VOLDi,d) $+N T \% i, t$, where $N i, t$ is the number of trading volume days of stock $i$ in month $t, R i, d$ is the absolute return on stock $i$ on day $d$, and $V O L D_{i, d}$ is the Chinese yuan trading volume of stock $i$ on day $d . N T \%_{i, t}$ is the percentage of zero-return days within a month.

\section{Conclusions}

This paper investigates the cross-sectional correlations between illiquidity and stock returns, with considering the NTS Reform in Shanghai A' Share stock market. Our main findings are shown as follows. Firstly, differing from prior studies, stock returns are decreasing in a stock's illiquidity (illiq zero) both before the NTS Reform and after the NTS Reform. This finding means that investors require higher compensation on liquid stocks than illiquid stocks. Thus we call there exists illiquidity puzzle in Shanghai A' share stock market. To seek for the negative correlation between illiquidity and stock returns, we then consider the impact of idiosyncratic volatility on illiquidity as well as stock returns by using bivariate sorts portfolio analysis. After considering the idiosyncratic volatility basis, stock returns show no clearly relations to illiquidity, especially after the NTS Reform. Lastly, we use residual approach to minimize the effect of idiosyncratic volatility, and find there exists a positive relation between illiq_zero and stock returns.

\section{References}

Acharya, V. V., \& Pedersen, L. H. (2005). Asset pricing with liquidity risk. Journal of Financial Economics, 77(2), 375-410. 
Amihud, Y. (2002). Illiquidity and stock returns: Cross-section and time-series effects. Journal of Financial Markets, 5(1), 31-56. Amihud, Y., \& Mendelson, H. (1986). Asset pricing and the bid-ask spread. Journal of Financial Economics, 17(2), $223-249$.

Ang, A., Hodrick, R. J., Xing, Y., \& Zhang, X. (2006). The cross-section of volatility and expected returns. The Journal of Finance, 61(1), 259-299.

Ang, A., Hodrick, R. J., Xing, Y., \& Zhang, X. (2009). High idiosyncratic volatility and low returns: International and further US evidence. Journal of Financial Economics, 91(1), 1-23.

Bali, T. G., \& Cakici, N. (2008). Idiosyncratic volatility and the cross section of expected returns. Journal of Financial and Quantitative Analysis, 43(1), 29-58.

Bali, T. G., Cakici, N., \& Whitelaw, R. F. (2011). Maxing out: Stocks as lotteries and the cross-section of expected returns. Journal of Financial Economics, 99(2), 427-446.

Bao, J., Pan, J., \& Wang, J. (2011). The illiquidity of corporate bonds. The Journal of Finance, 66(3), 911-946.

Brennan, M. J., Chordia, T., \& Subrahmanyam, A. (1998). Alternative factor specifications, security characteristics, and the cross-section of expected stock returns. Journal of Financial Economics, 49(3), 345-373.

Brennan, M. J., \& Subrahmanyam, A. (1996). Market microstructure and asset pricing: On the compensation for illiquidity in stock returns. Journal of Financial Economics, 41(3), 441-464.

Chen, G., Tu, H., \& Lin, H. (2007). Idiosyncratic volatility puzzle and explanations based on heterogeneous beliefs: Evidence from Chinese stock markets. Workingpaper, Xiamen University.

Chen, J., Hong, H., \& Stein, C. J. (2002). Breadth of ownership and stock returns. Journal of Financial Economics, 66(2-3), 171-205.

Chen, Y. (2015). An empirical study of liquidity and autocorrelations on Chinese stock markets. Asia-Pacific Financial Markets, 22(3), 261-282.

Chordia, T., Sarkar, A., \& Subrahmanyam, A. (2005). The joint dynamics of liquidity, returns, and volatility across small and large firms. Staff Report, Federal Reserve Bank of New York.

Datar, V. T., Naik, N. Y., \& Radcliffe, R. (1998). Liquidity and stock returns: An alternative test. Journal of Financial Markets, 1(2), 203-219.

Deng, X. C., \& Zheng, Z. L. (2011). Is there an idiosyncratic volatility puzzle exist in China's Equity Market. Journal of Business Economics, 1(1), 60-67.

Easley, D., Kiefer N. M., \& O'Hara, M. (1996). Liquidity, information, and infrequently traded stocks. The Journal of Finances, 51(4), 1405-1436.

Easley, D., \& O'Hara, M. (1987). Price, trade size, and information in securities markets. Journal of Financial Economics, 19(1), 69-90.

Easley, D., \& O'Hara, M. (2010). Microstructure and ambiguity. The Journal of Finances,65(5), 1817-1846.

Fama, E. F., \& French, K. R. (1992). The cross-section of expected stock returns. The Journal of Finance, 47(2), 427-465.

Fama, E. F., \& French, K. R. (1993). Common risk factors in the returns on stocks and bonds. Journal of Financial Economics, 33(1), 3-56.

Fama, E. F., \& French, K. R. (2008). Dissecting anomalies. The Journal of Finance, 63(4), 1653-1678.

Fama, E. F., \& MacBeth, J. D. (1973). Risk, return, and equilibrium: Empirical tests. The Journal of Political Economy, 81(3), 607-636.

Fu, F. (2009). Idiosyncratic risk and the cross-section of expected stock returns. Journal of Financial Economics, 91(1), $24-37$.

Han, Y., \& Lesmond, D. (2011). Liquidity biases and the pricing of cross-sectional idiosyncratic volatility. The Review of Financial Studies, 24(5), 1590-1629.

Ho, T., \& Stoll, H. R. (1980). On dealer markets under competition. The Journal of Finance, 35(2), 259-267.

Ho, T., \& Stoll, H. R. (1981). Optimal dealer pricing under transactions and return uncertainty. Journal of Financial Economics, 9(1), 47-73.

Hou, K., \& Loh, R. K. (2016). Have we solved the idiosyncratic volatility puzzle? Journal of Financial Economics, 121(1), 167-194.

Huang, W., Liu, Q., Rhee, S. G., \& Zhang, L. (2009). Return reversals, idiosyncratic risk, and expected returns. The Review of Financial Studies, 23(1), 147-168.

Jin, Y. H., \& Yang, W. (2002). An empirical analysis of stock price, trade volume and volatility on market liquidity. Journal of Financial Research, 264(6), 12-21.

Kalimipalli, M., \& Nayak, S. (2012). Idiosyncratic volatility vs. liquidity? Evidence from the US corporate bond market. Journal of Financial Intermediation, 21(2), 217-242. 
Kalimipalli, M., Nayak, S., \& Perez, M. F. (2013). Dynamic effects of idiosyncratic volatility and liquidity on corporate bond spreads. Journal of Banking \& Finance, 37(8), 2969-2990.

Khovansky, S., \& Zhylyevskyy, O. (2013). Impact of idiosyncratic volatility on stock returns: A cross-sectional study. Journal of Banking \& Finance, 37(8), 3064-3075.

Lesmond, D. A., Ogden, J. P., \& Trzcinka, C. A. (1999). A new estimate of transaction costs. The Review of Financial Studies, 12(5), 1113-1141.

Liu, W. (2006). A liquidity-augmented capital asset pricing model. Journal of Financial Economics, 82(3), 631-671.

Narayan, P. K., \& Zheng, X. (2010). Market liquidity risk factor and financial market anomalies: Evidence from the Chinese stock market. Pacific-Basin Finance Journal, 18(5), 509-520.

O'Hara, M. (2003). Presidential address: Liquidity and price discovery. The Journal of Finance, 58(4), 1335-1354.

Pástor, L., \& Stambaugh, R. F. (2003). Liquidity risk and expected stock returns. Journal of Political Economy, 111(3), $642-685$.

Stoll, H. R. (1978). The pricing of security dealer services: An empirical study of NASDAQ stocks. The Journal of Finance, 33(4), 1153-1172.

Spiegel, M. I., \& Wang, X. (2005). Cross-sectional variation in stock returns: Liquidity and idiosyncratic risk. Workingpaper, Yale ICF Working Paper No. 05-13, EFA Moscow Meetings Paper.

Su, D. W., \& Mai, Y. X. (2004). Liquidity and asset pricing: An empirical exploration of turnover and expected returns on Chinese stock markets. Economic Research Journal, 2, 95-105.

Vayanos, D., \& Wang, J. (2011). Liquidity and asset returns under asymmetric information and imperfect competition. The Review of Financial Studies, 25(5), 1339-1365.

Wu, Y. F., \& Song, F. M. (2007). Liquidity risk and stock return. Proceedings of the Operations Research and Management Science, 16(2), 117-122.

Yang, H. W., \& Han, L. Y. (2009). An empirical study of the relationship between the idiosyncratic volatility and cross-sectional return. Journal of Beijing University of Aeronautics and Astronautics (Social Sciences Edition), 1(22), 6-10.

Zhang, F., Tian, Y., \& Wirjanto, T. S. (2009). Liquidity risk and cross-sectional returns: Evidence from the chinese stock markets. Finance Research Letters, 6(4), 219-229. 